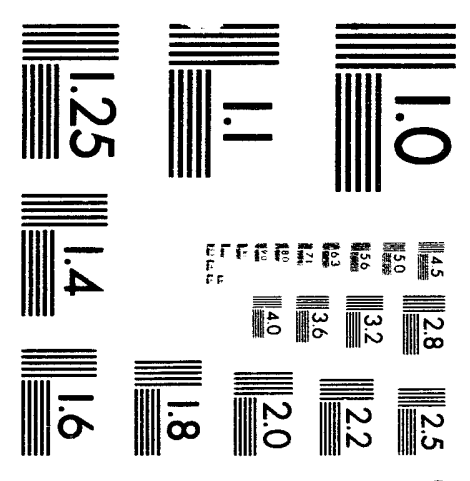



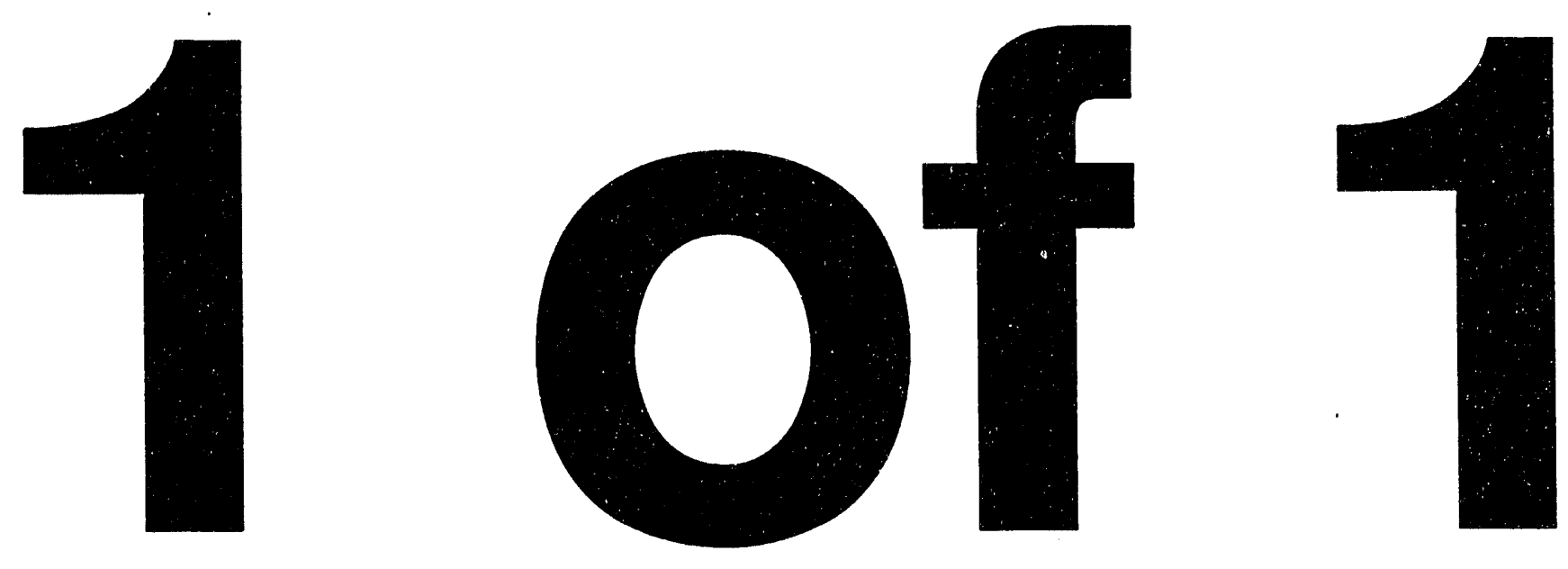


\section{Summary of Studies on Filter Clogging}

\section{VED \\ DEC 201993 \\ OSTI}

\section{Chi Tien}

(Amendment \#1 to Subcontract \#B160439)

Ending September 1993

September 1993

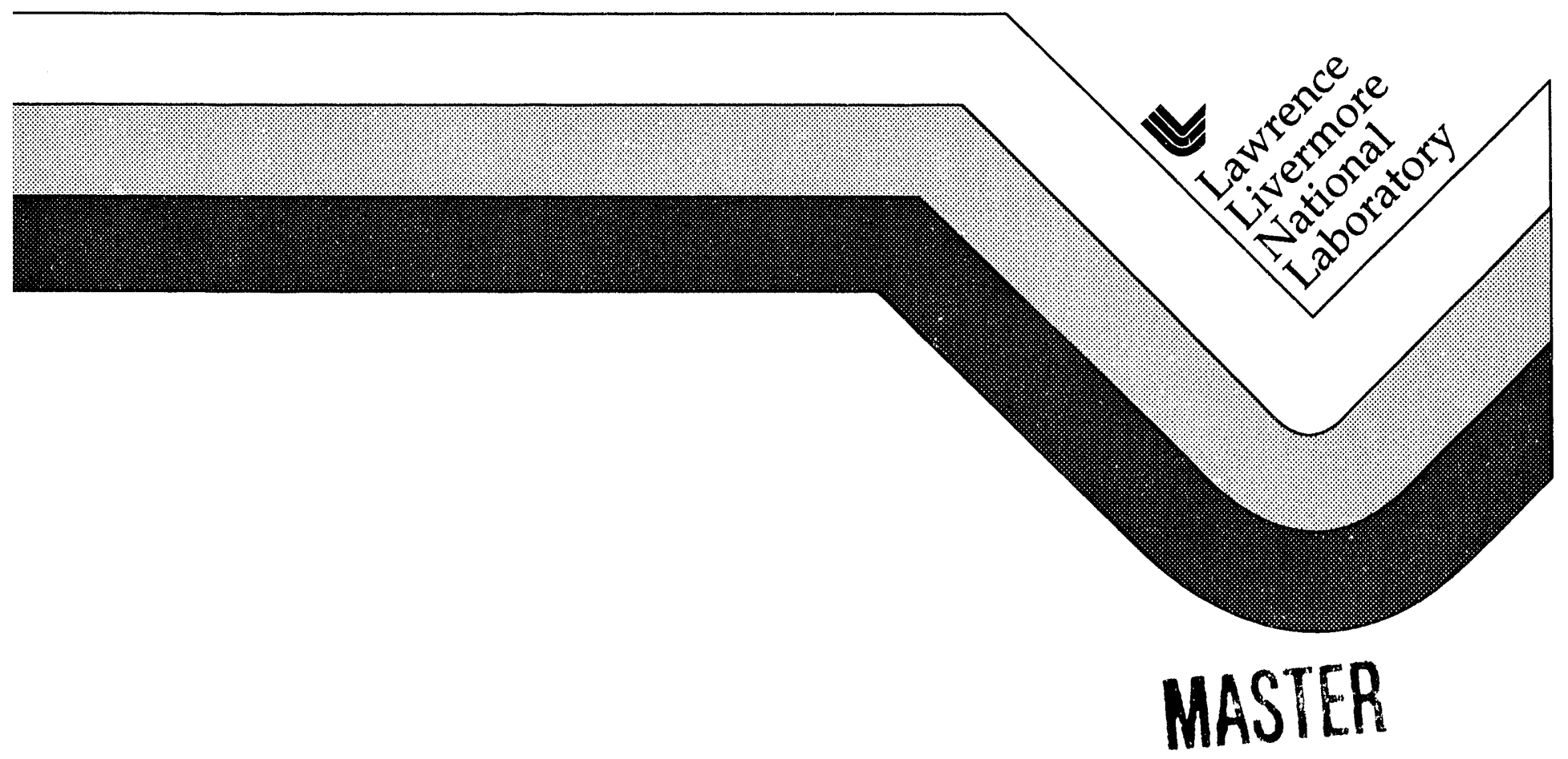

DISTRIBUTION OF THIS DOCUMENT IS UNLIMITED 


\section{DISCLAIMER}

Work performed under the auspices of the U.S. Department of Energy by Lawrence Livermore National Laboratory under contract number W-7405-ENG-48.

This document was prepared as an account of work sponsored by an agency of the United States Government. Neither the United States Government nor the University of California nor any of their empioyees, makes any warranty. express or implied, or assumes any legal liability or responsibility for the accuracy, completeness, or usefulness of any information, apparatus, product, or process disclosed, or represents that its use would not infringe privately owned rights. Reference herein to any specific commercial products, process, or service by trade name, trademark, manufacturer, or otherwise, does not necessarily constitute or imply its endorsement, recommendation, or favoring by the United States Government or the University of California. The views and opinions of authors expressed herein do not necessarily state or reflect those of the United States Government or the University of California, and shall not be used for advertising or product endorsement purposes. 


\section{Abstract}

The dynamic behavior of clogged filters is characterized by the changes of the local collection efficiency and permeability of the media as functions of the extent of deposition. Relevant literature on this topic is reviewed in this report. 


\section{Summary of Studies on Filter Clogging}

Depth filtration which employs either fibrous or granular media for retaining particles from fluid-particle suspensions is inherently non-steady in nature. As the extent of particle retention increases with time, the medium of a filter undergoes a continuing change in its media structure. Furthermore, as the extent of deposition is not uniform throughout the filter, this media structural change is both a local and time-dependent.

As a result of this filter media structural change, filter performance is a function of time. In both granular and fibrous filtration, the effluent concentration is often to decrease with time while the pressure required to maintain a constant throughput increases. While this behavior has been observed by many investigators in the past, quantitative analysis of filter clogging and its effect have begun only in more recent years. This review was aimed at examining some of the more important findings on this topic especially those aimed at developing generalized relationships which, in turn, may be applied in predicting filter performance.

To make the survey more complete, both aerosol and hydrosol filtration were included although the primary interest is on the former. The inclusion of the hydrosol studies was made since the results of some of these studies (at least their methodologies) can be easily extended to aerosol systems.

\section{Prediction of Filter Performance}

As the primary reason for studying filter clogging resides in its effect on filter performance, we will first briefly outline the procedure for predicting the dynamic behavior of depth filtration. The information required for the prediction largely determines the kind of filter clogging studies which have been carried out so far as well as the methods and format used for presenting the results.

The dynamic behavior of depth filtration can be obtained from the solution of the macroscopic conservation equation and the rate equation together with appropriate initial and boundary conditions. For the simplest case of monodispersed suspensions with negligible dispersion effect and constant suspension throughput, they are:

Macroscopic Conservation Equation

$$
u_{z} \frac{\partial c}{\partial z}+\frac{\partial \sigma}{\partial \theta}=0
$$

Rate Equation 


$$
\frac{\partial \sigma}{\partial \theta}=\lambda u_{s} c
$$

Initial and Boundary Condition

$$
\begin{gathered}
c=c_{\text {in }} \\
c=c_{i}, \quad \sigma=\sigma_{i}, \quad z \geq 0, \quad \theta \leq 0
\end{gathered}
$$

where the dependent variables are $z$, the axial distance and $\theta$, the corrected time, defined as $t-\int_{0}^{z}\left(\epsilon / u_{s}\right) d z$ with $t, \varepsilon$ and $u_{z}$ being the time, the filter porosity and the superficial velocity. $c$ denotes the concentration of particles in the suspension and $\sigma$ is the amount of deposited particles per unit filter volume. $\lambda$ is commonly referred to as the filter coefficient. The rate of filtration [i.e. Equation (2)] is assumed to be proportional to the particles available, or $u_{5} c$. $\lambda$ therefore may be viewed as a first order rate constant.

In aerosol filtration, the ability of a filter in retaining particles is often expressed by the so-called single collection efficiency, $n_{s}$. The relationship between $\lambda$ and $\eta_{s}$ is (Tien. 1989).

For Granular Filtration

$$
\lambda=\left[3\left(1-\epsilon_{0}\right) / 2\right]\left(\eta_{s} / d_{8}\right)
$$

For Fibrous Filtration

$$
\lambda=\left[4\left(1-\epsilon_{0}\right) / \pi\right]\left(\eta_{S} / d_{f}\right)
$$

where $\varepsilon_{0}$ is the initial filter porosity and $d_{f}\left(\right.$ or $\left.d_{g}\right)$ is the fiber (or grain) diameter. 
Initially, when a filter is free of any deposited particles, and the filter media is homogeneous, $\lambda$ is constant throughout the entire filter and has the value of $\lambda_{o}$ (i.e. initial filter coefficient). As deposition takes place within the filter and the media undergoes change, $\lambda$ changes accordingly. To account for their clogging effect, one may write

$$
F(\alpha, \sigma)=\lambda / \lambda_{0}=\eta_{s}\left(\eta_{s}\right)_{0}
$$

where $\underline{\alpha}$ is a parameter vector characteristic of the clogging process. One may expect that the components of $\underline{\alpha}$ may include the various relevant dimensionless parameters such as the Stokes number interception parameter, etc.

The pressure drop, $\Delta \mathrm{p}$, necessary to maintain a constant throughput may be obtained as

$$
\Delta p=(\Delta p) \int_{0}^{L} \frac{(\partial p / \partial z)}{(\partial p / \partial z)_{0}} d z
$$

where $\Delta \mathrm{p}_{0}$ is the initial value of $\Delta \mathrm{p}$ when the filter is clean and $\mathrm{L}$ is the filter depth. The required pressure gradient ratio represents the effect of filter clogging to flow, or

$$
G(\beta, \sigma)=\frac{(\partial p / \partial z)}{(\partial p / \partial z)_{0}}
$$

In principle, the filter performance may be predicted for the solution of Equations (1) (4). Once the extent of deposition through the filter at different times is known, Equation (7) can be used to obtain the $\eta_{\mathrm{s}}$ required pressure drop. For this type of prediction, the value of $\lambda_{\mathrm{o}}$ (or $\left.\eta_{\mathrm{s}}\right)$ and $(\Delta \mathrm{p})_{\mathrm{o}}$, and the functions $\mathrm{F}$ and $\mathrm{G}$ are required. Thus, the practical purpose of filter clogging research in the determination of $F$ and $G$.

\section{Studies of Determining F and G}

Studies of filter clogging aimed at determining $F$ and $G$ have been made by a number of investigators in the past. Depending upon the principle used for determining $F$ (or $G$ ), one may classify the studies into the following categories:

(A) Experimental Determination of F and G 
(B) Prediction of F and G Based on Assumed Capture Mechanism and Deposit Morphology

(C) Stochastic Simulation

A summary of these studies according to the above classification is given below:

(A) Determination of $F$ and $G$ from Experimental Data. The difficulty involved in determining $F$ and $G$ from experiments arises from the fact that the extent of clogging varies spatially while the experimental results (e.g. effluent concentration) represent the overall filter behavior. One may therefore adopt an optimization-search procedure by matching the predicted filter performance based on assumed $F$ and $G$ with experimental data (which may be called the integral approach). Alternately, one may obtain $F$ and $G$ using a limiting process (to a single collecting body) or conducting measurements using a single collecting. element or its equivalent (or the differential approach).

A summary of the various $F$ and $G$ obtained by earlier investigators using the integral approach is listed in Table 1. Note that these results apply almost exclusively to hydrosols. Furthermore, since they were obtained based on data of specific systems. Consequently, it would be difficult to extend these results for general use.

For aerosol filtration in granular media, Tien and coworkers (Walata et al., 1986; Takahashi et al., 1986; and Jung and Tien, 1991) established general correlations for predicting the clogging effect using the differential approach. The results may be given as

$$
\begin{aligned}
& F=1+\alpha_{1} \sigma^{\alpha_{2}} \\
& G=1+\beta_{1} \sigma^{\beta_{2}}
\end{aligned}
$$

The coefficient $\alpha_{1}$ and $\beta_{1}$ and exponents $\alpha_{2}$ and $\beta_{2}$ are found to be functions of the Stokes numbers, $\mathrm{N}_{\mathrm{St}}$ and the interception parameter, $\mathrm{N}_{\mathrm{R}}, \alpha_{2}$ and $\beta_{2}$ are found to be:

$$
\begin{aligned}
& \alpha_{2}=0.4416 N_{S t}^{-0.3649} N_{R}^{0.297} \\
& \beta_{2}=3.5134 N_{S t}^{-0.0925} N_{R}^{0.2748}
\end{aligned}
$$

The coefficients $\alpha_{1}$ and $\alpha_{2}$ are 


$$
\begin{aligned}
& \alpha_{1}=[F-1]_{\sigma=10^{-3}}\left(10^{-3}\right)^{\alpha_{2}} \\
& \alpha_{2}=[G-1]_{0=10^{-3}}\left(10^{-3}\right)^{\beta_{2}}
\end{aligned}
$$

The quantities $[\mathrm{F}-1]_{\sigma=10.3}$ and $[\mathrm{G}-1]_{\sigma=10.3}$ are

$$
\begin{aligned}
& {[F-1]_{\sigma=10}^{-3}=0.0955 N_{S t}^{-1.478} N_{R}^{0.4322}} \\
& {[G-1]_{\sigma=10}^{-3}=0.3484 N_{S t}^{-1.199} N_{R}^{0.2397}}
\end{aligned}
$$

The Stokes and interception parameter are defined as

$$
\begin{gathered}
N_{S t}=\left(\rho_{p} d_{p}^{2} u_{s} c_{s}\right) /(9 \mu d g) \\
N_{R}=d_{p} / d_{g}
\end{gathered}
$$

where $\rho_{p}$ and $d_{p}$ are the particle density and diameter $\mu$, the viscosity of gas and $c_{s}$ the Cunningham correction factor.

The results of $F$ and $G$ as functions of $\sigma$ are shown in Fig. 1.

Tien and coworkers [Emi et al., 1982; Tsiang et al., 1982] also studied filter clogging of fibrous filtration. These studies were made using model filters of a single layer (parallel fibers on wire screens) so that the results may be directly related to the collector efficiencies of the fiber element and explicit relationships may be established between the operating variables and the effect of filter clogging. On the other hand, it is difficult to extend these results to fibrous filters unless extraneous assumption concerning the spatial distribution of fiber along the axial direction are made.

The results of Emi et al. may be expressed as

$$
\left(\eta / \eta_{0}\right)=1+\left(m / m_{0}\right)^{b}
$$


where $m_{0}$ and $b$ are two empirical parameters. $m$ is the amount of deposits per unit surface area of the wire screen $\left(\mathrm{kg} / \mathrm{m}^{2}\right) . m_{0}$ is given as

$$
m_{0}=A \eta_{0} u_{s}^{0.25}
$$

where $u_{s}$ is given in $\mathrm{cm} \mathrm{s}^{-1}$. Both $A$ and the exponent $b$ of Equation (15) are functions of the wire screen uses. They are:

Mesh Size of Screen

200 mesh

325 mesh

500 mesh
A

$2.7 \times 10^{-3}$

$1.5 \times 10^{-3}$

$1.1 \times 10^{-3}$ b

1.15

1.23

1.34

The discussion of the results of Tsiang et al. will be deferred to later sections.

(B) Formulation of F and G Based on Assumed Capture Mechanism and Deposition Morphology.

(B-1) For aerosol filtration in fibrous media, Payatakes and Tien (1976) assumed that particle deposition results in deposits found in dendrite form and proposed a set of equations describing the growth of these dendrites on the assumption that particle collection is due to the interception. Payatakes and coworkers (Payatakes, 1976, 1977; Payatakes and Graydon. 1976, 1980; Payatakes and Okyyama, 1981) subsequently refined and extended this concept to include the effects of inertial impaction, Brownian diffusion as well as others in particle capture. A typical set of the results is given in Fig. 2. Although the method used for predicting the relationship of $F$ vs. $\sigma$ and $G$ vs. $\sigma$ involves fairly tedious calculations, the results obtained, in general, may be filtered in the form of either Equations (9.a) and (9.b) or as a third degree polynomial of $\sigma$, which, in turn, can be used for predicting filter performance.

(B-2) For filtration in granular media, O'Melia and Ali (1978) argued that deposited particles may be considered as additional collectors, thus enhancing the filter performance. An iterated procedure was proposed for the incremental increase in $\eta$ leading to a calculation of $c_{\mathrm{eff}}$ as a function of time. Two adjustable parameters were introduced to insure agreement between experiments and prediction.

In order to generalize the use of the model of O'Melia and Ali, Vigneswaran and workers (Tien, 1984) attempted empirical correlations of these adjustable parameters with operating variables. The accuracy of the correlations was found to be rather marginal.

The O'Melia and Ali model has only been used in representing hydrosol systems. It is not certain to what degree it may be applied to aerosols. 
(B-3) Tien et al. (1979) developed a method for producing the effect of deposition in depth filtration. This method is based on the recognition that the effect of deposition may increase the effective dimension of the collecting bodies (through the formation of deposits outside fibers or grains) or block the flow of suspensions through certain pore constrictions. Although their effects may occur simultaneously, Tien et al. assumed that the former effect is significant during the initial period of filtration while pore blockage occurs only if the extent of deposition is significant. This model has been found to give reasonable representation of experimental data of hydrosol filtration collected by a number of investigators. Like the model of O'Melia and Ali, its use has only been extended to aerosols.

(B-4) As a further refinement of the model of Tien et al. (1979), Gutfinger et al. (1988) and Fichman et al. (1988) argued that deposit layers are porous and therefore permeable. A modified Happel flow field was then determined on the condition that the deposit layer is uniform in thickness. Based on this new flow field, one can readily calculate the collector efficiency and hence the function $F$ under various conditions.

The work reported by Fichman et al. and Gutfinger et al., however, did not provide sufficient results to determine the accuracy of their model.

C. Stochastic Simulation. A conceptual simple way of analyzing the effect of filter clogging is through computer experiment of the deposition process. Such an approach for predicting filter performance was outlined by Tien et al. (1977) and Wang et al. (1977) and was applied in both aerosol and hydrosol filtration.

The principle of stochastic simulation may be described as follows. Consider a fluid stream flowing toward a spherical collector. At a distance far away from the collector, a control surface may be set up with a sufficient layer cover such that only the particles which may be controlled by the collector will pass through the control surface (see Fig. 3). One can then assign positions to the incoming particles. By determining their trajectories and following these trajectories sequentially and by using various particle adhesion criteria, one can readily determine whether a particular incoming particle will be deposited or not, and in the case of deposition, the position of deposition. Thus through simulation, one may obtain the number of particles deposited as a function of the number of particles approaching the collector as well as the positions of deposited particles. The latter information gives the morphology of deposits as well as its evolution. For the former, one may determine the instantaneous collector efficiency to be

$$
\eta=\frac{\partial N}{\partial M}
$$

where $\mathrm{N}$ and $\mathrm{M}$ denote, respectively, the number of deposited particles and the number of particles approaching the collector. The function $F$ is 


$$
F=\eta / \eta_{0}
$$

and

$$
\eta_{0}=\lim _{M \rightarrow 0} \frac{\partial N}{\partial M}
$$

The corresponding $\sigma$ is

$$
\sigma=(N)(\pi / 6)\left(d_{p}^{3} / V\right)(1-\epsilon)
$$

where $\mathrm{V}$ is the volume of the collector.

This stochastic technique has been used to predict the effect of filter clogging for aerosol filtration in fibrous and granular media.

(C-1) Aerosol Filtration in Fibrous Model Filters. The simulation study conducted by Tsiang et al. (1982) considers aerosol filtration in a model filter composed of parallel filters. Simulation was conducted assuming the flow field around the parallel fibers was given by the Miyagi solution (Miyagi, 1958). The adhesion criterion was that the normal component of the impacting velocity must be less than the capture limit velocity as postulated by Dahneke (1972, 1973). By adjusting the values of the various material constant values in determining the adhesion criterion, good agreement between simulation and experiment was established as shown in Fig. 4.

(C-2) Aerosol Filtration in Granular Media. More recently, Jung (1991) developed a simulation procedure for studying aerosol filtration in granular media. In order to account for the possible particle bounce-off, the change of flow field due to deposition as well as the hydrodynamic retardation effect, Jung introduced an empirical correction factor - the capture probability and applied it in determining the adhesion of impacting particles. This capture probability was found to be a function of the Stokes number and interception parameter. A comparison of the relationship of F vs. $\sigma$ determined from the simulation with experiments is shown in Fig. 5.

Generally speaking, both the work of Tsiang et al. and Jung were found to give good agreement with experiments. However, this agreement was obtained by adjusting the condition of adhesion for impacting particles. This plus the excessive computational requirement makes the use of simulation as it is formulated presently in practical applications questionable.

D. In addition to the various studies mentioned above, there are two additional studies on the effect of deposition. Chiang and Tien (1985a \& b) developed an expression of $F$ on the basis that the effect of deposition may be described as a combination of the dendrite 
growth and the formation of deposit layers outside filter grains. The former process was examined by using the stochastic simulation technique described in (C) while the latter process is studied as a moving-boundary problem using the constricted-tube model for media characterization. The weighting factors assigned to each of these two processes were determined empirically. For hydrosol filtration in granular media, $\mathrm{F}$ is found to be

$$
F=\eta / \eta_{0}=1+\left[492-\left(1.1 \times 10^{4}\right) N_{R}+\left(1.46 \times 10^{5}\right) N_{R}^{2}\right]
$$

Mackie et al. (1987) suggested that macroscopically the effect of deposition may be described in terms of the presence of a growing deposit layer outside filter grains. On the other hand, microscopically, one must consider the dendrite growth and view the outermost deposited particles as collectors. By using such an assumption and applying certain averaging processes for the random distribution of approaching aerosols, Mackie et al. developed a procedure for determining the instantaneous collection efficiency incrementally. A comparison of Mackie's prediction with experiments of hydrosol filtration in granular media in terms of $\lambda$ vs. $\sigma$ is shown in Fig. 6. Although the agreement is only fair, the prediction is in qualitative agreement with experiments.

\section{Model Comparisons}

A part of this literature review, a comparison of some of the studies cited above was made. The comparison was between the work of Tien et al. (1979) mentioned in (B-3), the filter ripening model of O'Melia and Ali of (B-2), Equation (20) and the model of Fichman et al. (1989) for hydrosol filtration in granular media in the form of $\lambda / \lambda_{0} v s$. $\sigma$. The comparison is shown in Fig. 7.

The results shown in Fig. 7 demonstrated rather convincingly that these various studies give results with significant discrepancy. In spite of the fairly large number of studies carried out so far, a complete solution to the problem of filter clogging is not yet available.

\section{Calculations of Effluent Histories}

As stated before, the performance of a deep-bed filter can be predicted from the solution of Equations (1) - (4). With the change of the filter coefficient (or unit collector efficiency) with deposition given by the format of Equatrion (9.a), the effluent concentration (penetration) history can be readily obtained as follows.

The solution of Equations (1) - (4) may be written as (Tien, 1989):

$$
\frac{c}{c_{\text {in }}}=\frac{\sigma}{\sigma_{i n}}
$$




$$
\begin{gathered}
\frac{d \sigma}{d z}=-\lambda_{t,} \sigma\left(1+\alpha_{1} \sigma^{\alpha_{2}}\right) \\
\sigma=\sigma_{i n}, \quad z=0 \\
\frac{d \sigma_{i n}}{d \theta}=u_{s} \lambda_{i}\left(1+\alpha_{1} \sigma_{i n}^{\alpha_{2}}\right) c_{i n} \\
\sigma_{i n}=\sigma_{i n}, \quad \theta=0
\end{gathered}
$$

where $\sigma_{i n}$ is the value of $\sigma$ at $z=0$.

The effluent concentration history can be found by first solving (23.a) and (23.b), which give $\sigma_{\text {in }}$ as a function of $\theta$. This information can then be used to obtain the solution of Equation (22.a) which give the profile of $\mathrm{c}$ for an arbitrary time. Once $\sigma$ and $\sigma_{\text {in }}$ are known, the effluent concentration history can be found from Equation (21) with $z=L$. Note that the solution of Equations (23.a) and (23.b) can be obtained using a number of schemes. For the case of $\alpha_{2}=1$, an analytical solution is available and is given as (Tien, 1989)

$$
\frac{c}{c_{\text {in }}}=\frac{\exp \left[-u_{s} \lambda_{c} c_{\text {in }} \alpha_{1} \theta\right]}{\exp \left[\lambda_{0} z\right]+\exp \left[-u_{s} \lambda_{0} c_{\text {in }} \alpha_{1} \theta\right]-1}
$$




\section{Literature Cited}

Chiang, H.W. and C. Tien, AIChE J., 31, 1340 (1985a).

Chiang, H.W. and C. Tien, AIChE J., $\underline{31}, 1360$ (1985b).

Dahneke, B., J. Colloid Interface Sci., 40, 1 (1972).

Dahneke, B., J. Colloid Interface Sci., $\underline{45}, 584$ (1973).

Emi, H., C.S. Wang and C. Tien, AlChE J., 28, 397 (1982).

Fichman, M., C. Gutfinger and D. Pnueli, J. Aerosol Sci., 19, 425 (1988).

Gutfinger, C., D. Pnueli and M. Fichman, J. Aerosol Sci., 19, 443 (1989).

Jung, Yongwon, "Granular Filtration of Monodispersed and Polydispersed Aerosols," Ph.D. Dissertation, Syracuse University (1991).

Jung, Yongwon and C. Tien, J. Aerosol Sci., 22, 187 (1991).

Mackie, R.I., R.M.W. Horner and R.J. Jarvis, AIChE J., 33, 1761 (1987).

O'Melia, C.R. and W. Ali, Prog. Water Technol., $\underline{10,} 167$ (1978).

Miyagi, T., J. Phys. Soc. Japan, 13, 493 (1958).

Payatakes, A.C. and C. Tien, J. Aerosol Sci., I, 85, (1976).

Payatakes, A.C., Powder Technol., 14, 267 (1976).

Payatakes, A.C., AIChE J., 23, 192 (1977).

Payatakes, A.C. and L. Graydon, Chem. Eng. Sci., 1083 (1983).

Payatakes, A.C. and K. Okuyama, Proceedings of the International Symposium on Powder Technology, p., (1981).

Takahashi, T., S.A. Walata and C. Tien, AIChE J., $\underline{32}, 684$ (1986).

Tien, C., R.M. Turian and H. Pendse, AIChE J., 25, 385 (1979).

Tien, C., C.S. Wang and D.T. Barot, Science, 196, 983 (1977).

Tien, C., "Granular Filtration of Aerosols and Hydrosols," Butterworths (1989). 
Tsiang, R.C., C.S. Wang and C. Tien, Chem. Eng. Sci., 37, 1661 (1982).

Walata, S.A., T. Takahashi and C. Tien, Aerosol Sci. Technol., $\underline{5}, 23$ (1986). 


\section{Sources of Table 1}

Camp, T.R., Proc. ASCE, J. Sanitary Eng. Div., 90, 3 (1964).

Deb, A.K., Proc. ASCE, J. Sanitary Eng. Div., 95, 399 (1969).

Ives, K.J., Proc. Inst. Civil Engrs. (London), 16, 189 (1960).

Ives, K.J., Proc. ASCE, J. Sanitary Eng. Div., 87, 23 (1961).

Ives, K.J., "Theory of Filtration," special subject No. 7, Int'l Water Supply Congress and Exhibition, Vienna (1969).

Iwasaki, T., J. Am. Water Works Assoc., 29, 1591 (1937).

Heertjes, R.M., and C.F. Lerk, Trans. Inst. Chem. Engrs., 45, T138 (1967).

Mackrle, V., O. Draka, and J. Svec., "Hydrodynamics of the Disposal of Low Level Liquid Radioactive Wastes in Soil," Int'l Atomic Energy Agency, Contract Report No. 98, Vienna (1965).

Maroudas, A., and P. Eisenklam, Chem. Eng. Sci., 20, 875 (1965).

Mehter, A.A., R.M. Turian, and C. Tien, "Filtration in Deep Beds of Granular Activated Carbon," $\quad$ Research Report No. 70-3, FWPCA Grant No. 17020 0Z0, Syracuse University (1970).

Mints, D.M., "Modern Theory of Filtration," Special Report No. 10, International Water Supply Congress, Barcelona (1966).

Ornatski, N.V., E.V. Sergeev, and Y.M. Shekhtman, "Investigations of the Process of Clogging of Sands," Univ. of Moscow (1955).

Shekhtman, Y.M., "Filtration of Suspensions of Low concentrations," Inst. of Mechanics, U.S.S.R. Academy of Science (1961).

Stein, P.C., "A Study of the Theory of Rapid Filtration of Water Through Sand," D. Sc. Thesis, MIT (1940). 
Table 1

(A) List of Expressions for $F(\underline{\alpha}, \boldsymbol{\sigma})$

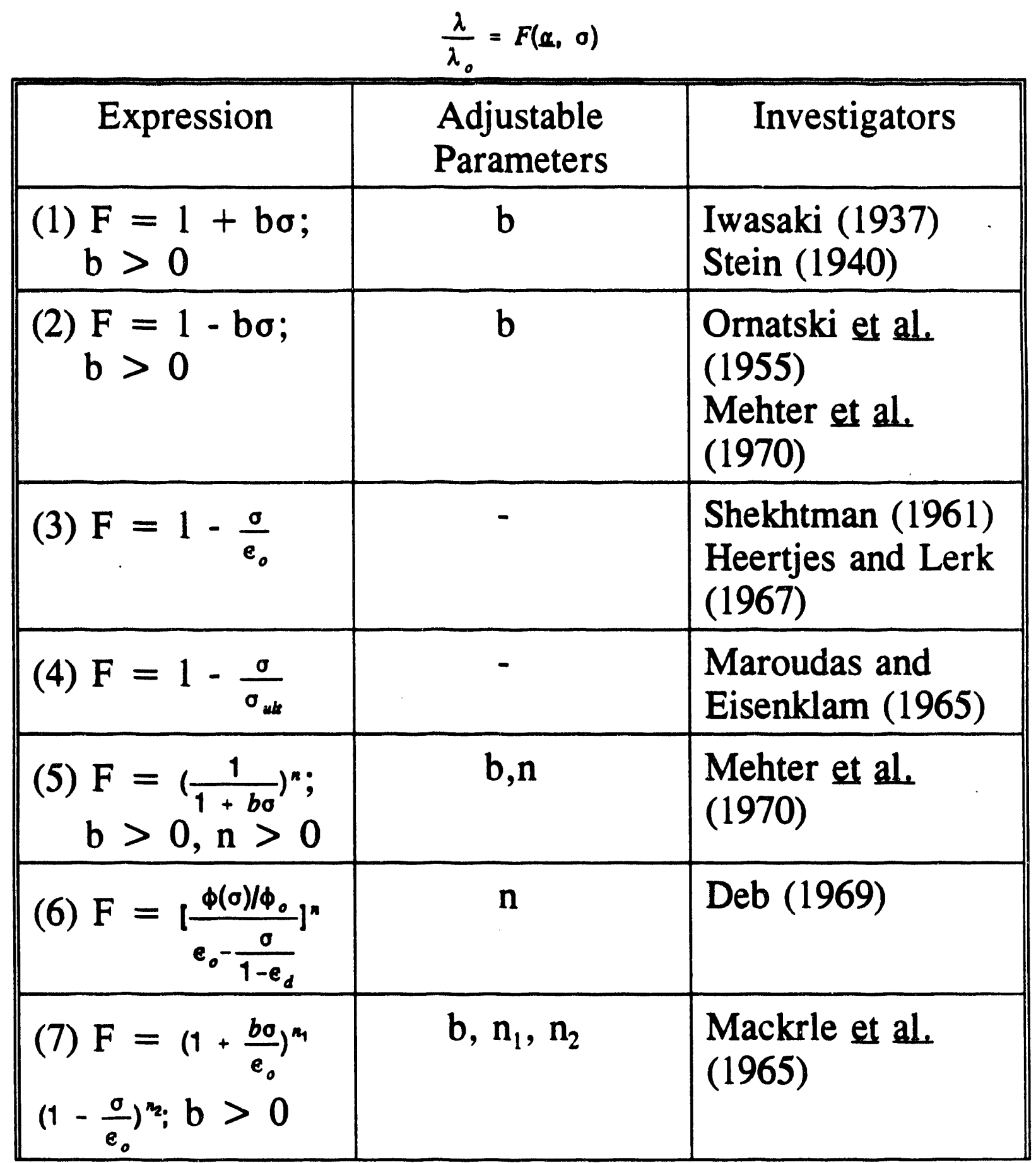




\begin{tabular}{|c|c|c|}
\hline $\begin{array}{l}\text { (8) } F=1+b \sigma- \\
\frac{a \sigma^{2}}{\varepsilon_{o}-\sigma} ; b>0, \\
a>0\end{array}$ & $a, b$ & Ives (1960) \\
\hline $\begin{array}{l}\text { (9) } F= \\
\left(1+\frac{b_{0}}{\epsilon_{0}}\right)^{n_{1}}\left(1-\frac{\sigma}{\epsilon_{0}}\right)^{n_{2}} \\
\left(1-\frac{\sigma}{\sigma_{u b}}\right)^{n_{3}} ; \\
b>0\end{array}$ & $\begin{array}{l}\mathrm{b}, \mathrm{n}_{1}, \\
\mathrm{n}_{2}, \mathrm{n}_{3}\end{array}$ & Ives (1969) \\
\hline
\end{tabular}


(B) List of Expressions for Function $G(\beta, \sigma)$

$$
\frac{(\alpha P / \alpha z)}{(\alpha P / \alpha z)_{0}}=G(\beta, \sigma)
$$

\begin{tabular}{|c|c|c|}
\hline Expression & Adjustable Parameters & Investigators \\
\hline (1) $G=1+d o ; d>0$ & d & Mehter et al, (1970) \\
\hline (2) $G=1+d \frac{\sigma}{\varepsilon_{o}} ; d>0$ & d & Mints (1966) \\
\hline $\begin{array}{l}\text { (3) } G=\left(\frac{1}{1-d \sigma}\right)^{m_{1}} \\
d>0, m_{1}>0\end{array}$ & $\mathrm{~d}, \mathrm{~m}_{1}$ & Mehter et al,, (1970) \\
\hline $\begin{array}{l}\text { (4) } G= \\
\left(1-\frac{2 \sigma}{\tilde{\beta}}\right)^{-1 / R_{j}} \tilde{\beta}>0\end{array}$ & - & $\begin{array}{l}\text { Maroudas and Eisenklam } \\
\text { (1965) }\end{array}$ \\
\hline $\begin{array}{l}(5) \mathrm{G}= \\
\left\{1+d\left[1-10^{-m_{1} o /\left(1-e_{d}\right)}\right]\right\} \\
\left\{\frac{e_{0}}{\epsilon_{0}-\frac{\sigma}{1-e_{d}}}\right\}^{3}\end{array}$ & $\mathrm{a}, \mathrm{m}_{1}$ & Deb (1969) \\
\hline $\begin{array}{l}\text { (6) } \mathrm{G}= \\
\left(1+\frac{d \sigma}{e_{0}}\right)^{m_{1}}\left(1-\frac{\sigma}{e_{0}}\right)^{m_{2}} \\
\mathrm{~d}>0, \mathrm{~m}_{1}>0, \mathrm{~m}_{2}>0\end{array}$ & $d, m_{1}, m_{2}$ & Ives (1969) \\
\hline $\begin{array}{l}(7) \mathrm{G}=1+\mathrm{f}\left\{\left(\lambda_{0}+\mathrm{d} \varepsilon_{0}\right) \sigma\right. \\
+ \\
\left(\frac{e+d}{2}\right)^{2}+d \varepsilon_{0}^{2} \ln \left(\frac{e_{0}-\sigma}{e_{0}}\right) \\
\mathrm{f}, \mathrm{d}, \mathrm{e}>0\end{array}$ & $f, d, e$ & Ives (1961) \\
\hline
\end{tabular}




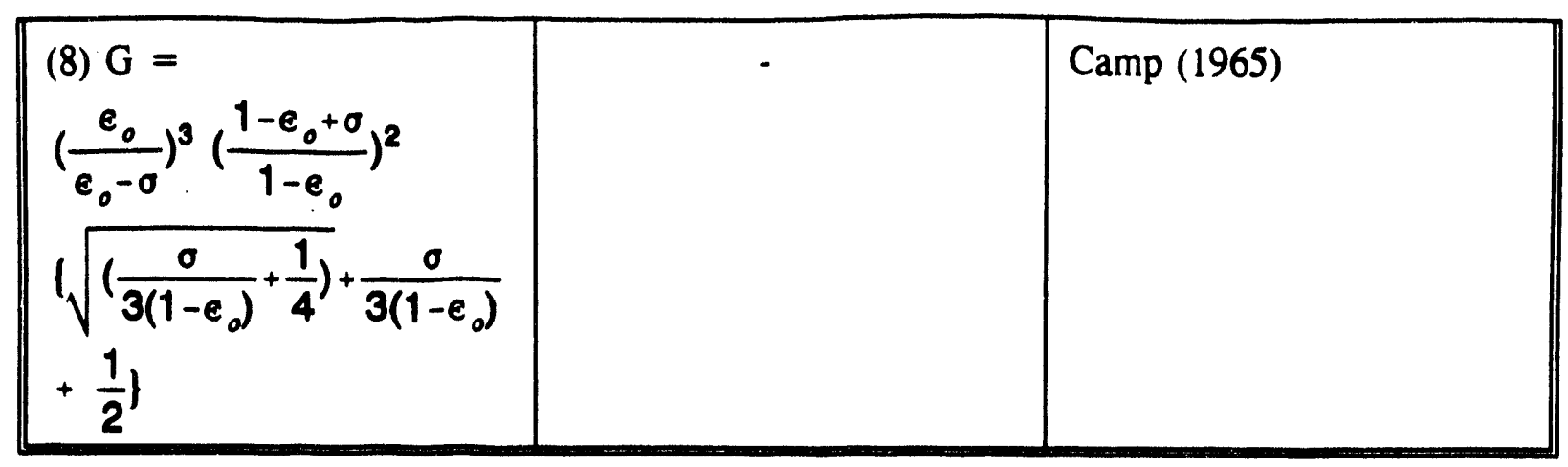



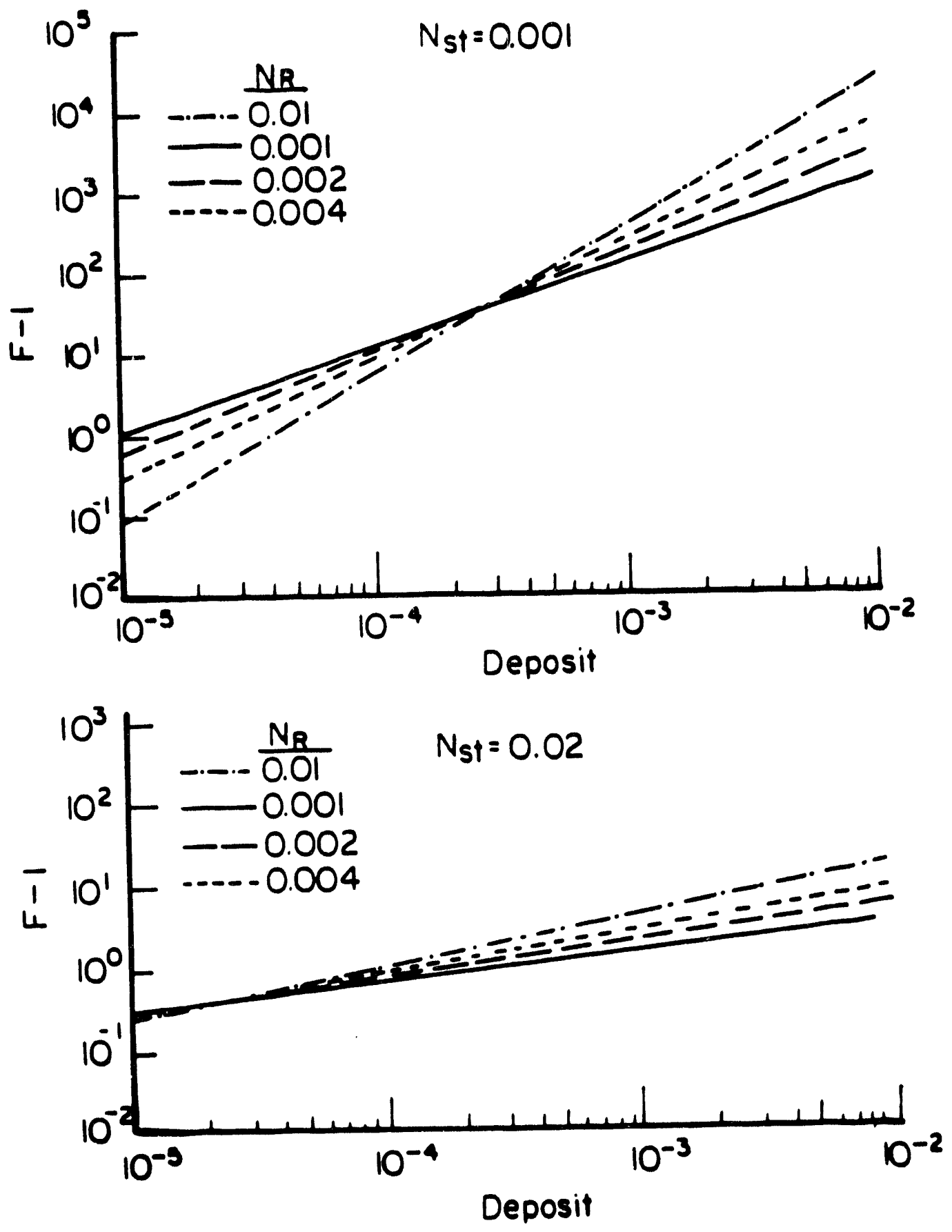

Fig. 1a Increase in pressure gradient due to deposition according to equation (9a). 

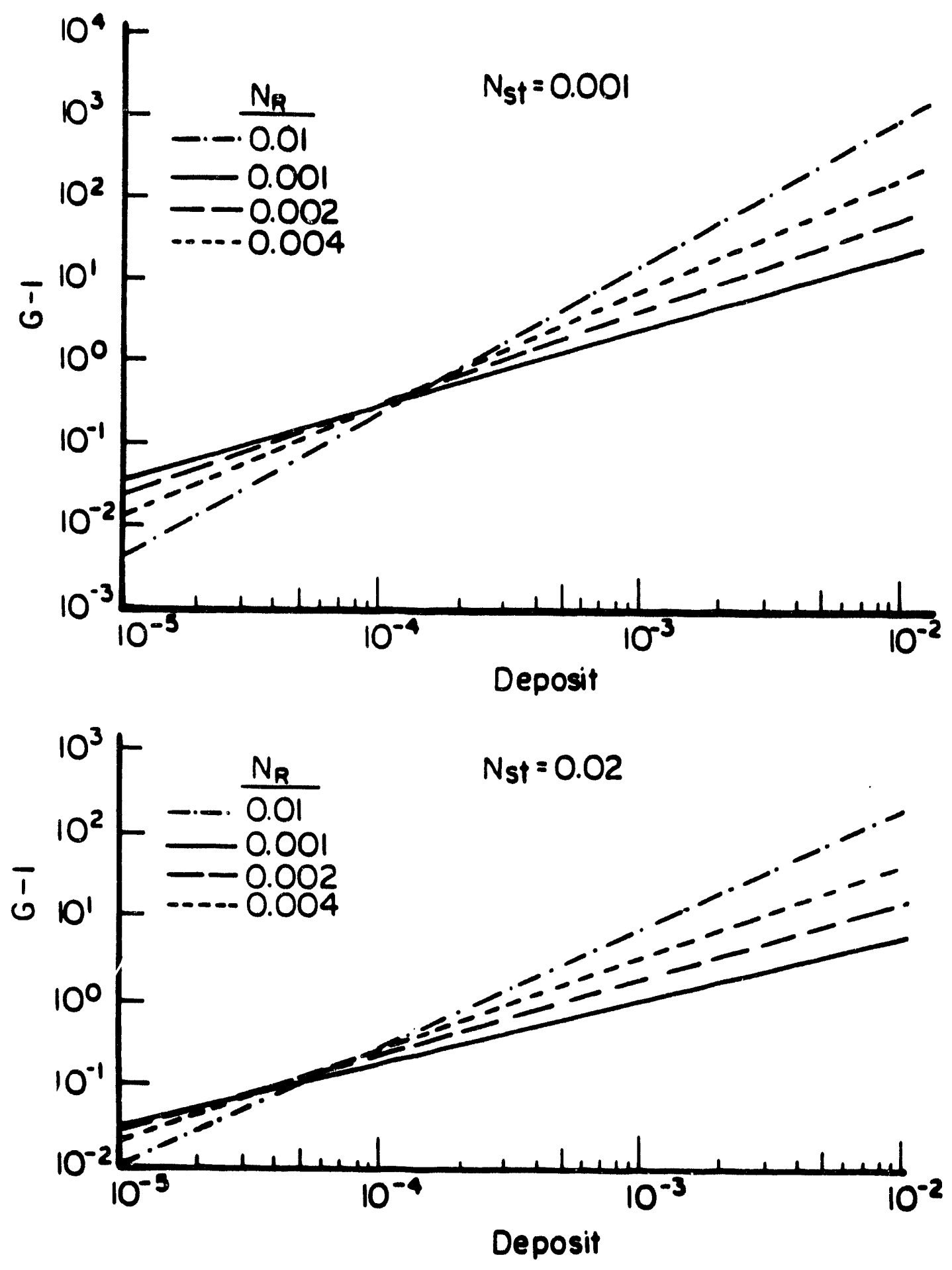

Fig. 1b Increase in pressure gradient due to deposition according to equation (9b). 


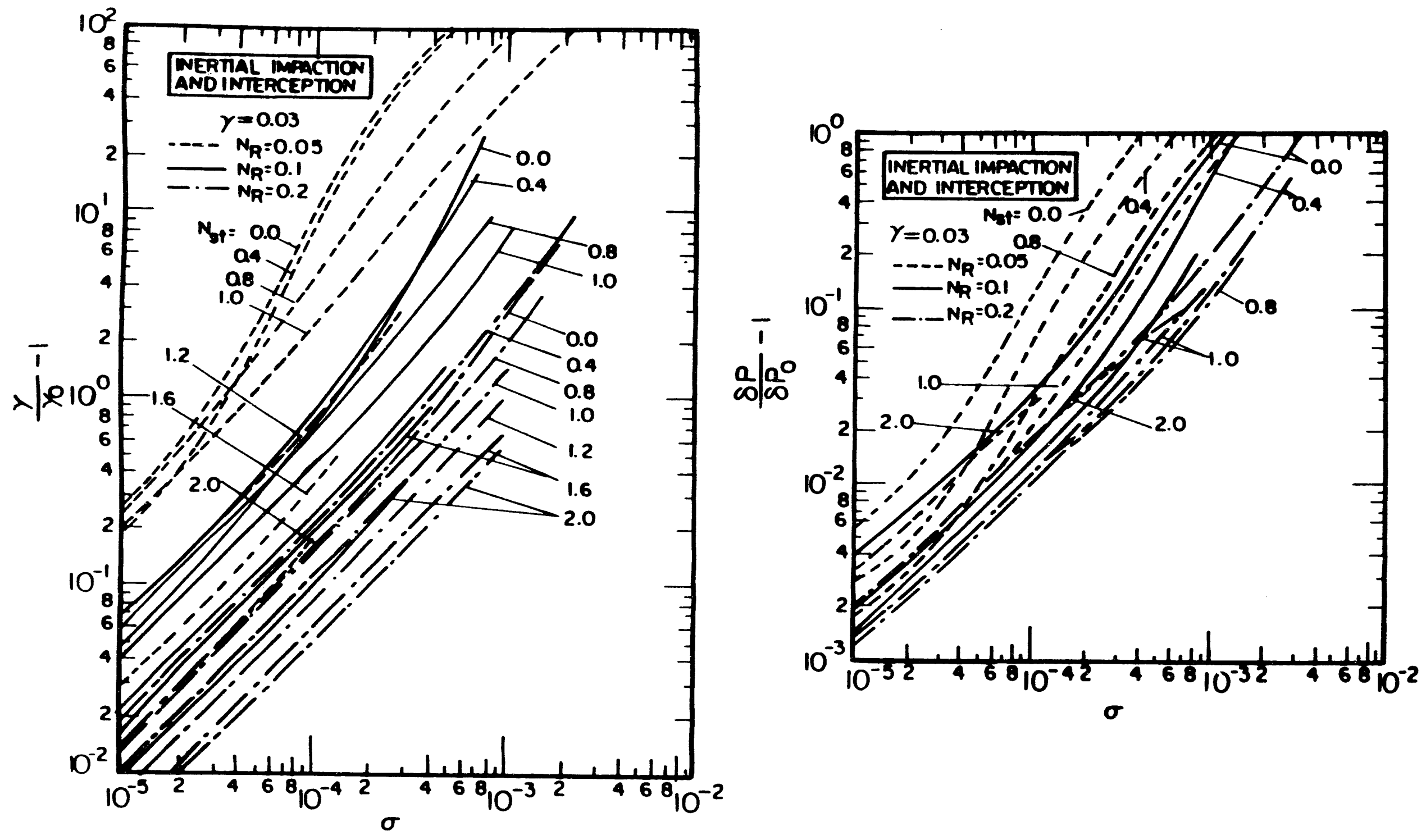

Fig. 2 Prediction of $F$ and $G$ for aerosol fitration in fibrous media according to Paystakes and Okuyame (1981). $\gamma$ denoles packing density $\left(\gamma=1-\varepsilon_{0}\right)$. 


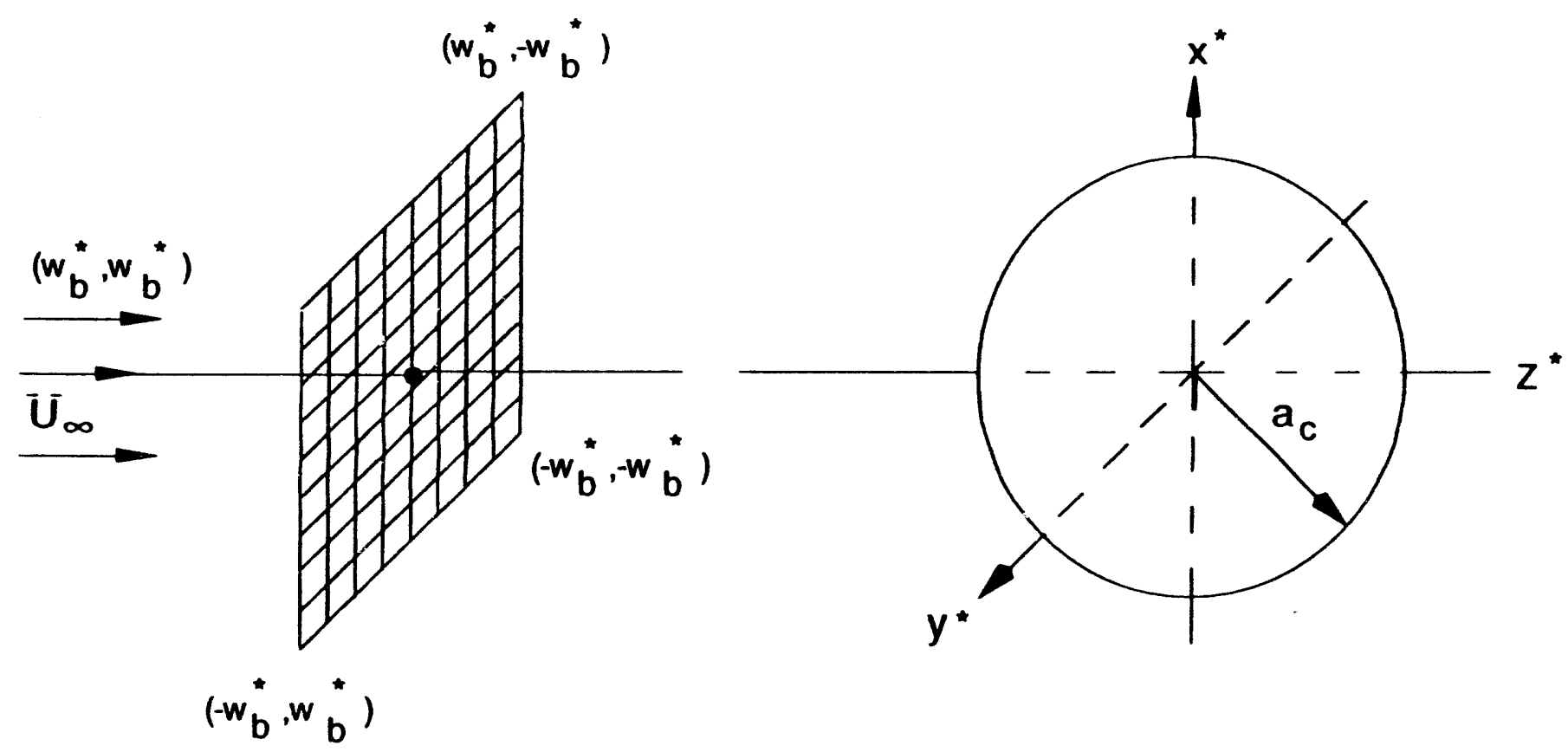

Fig.3 Schematic representation of simulating deposition on a spherical collector 


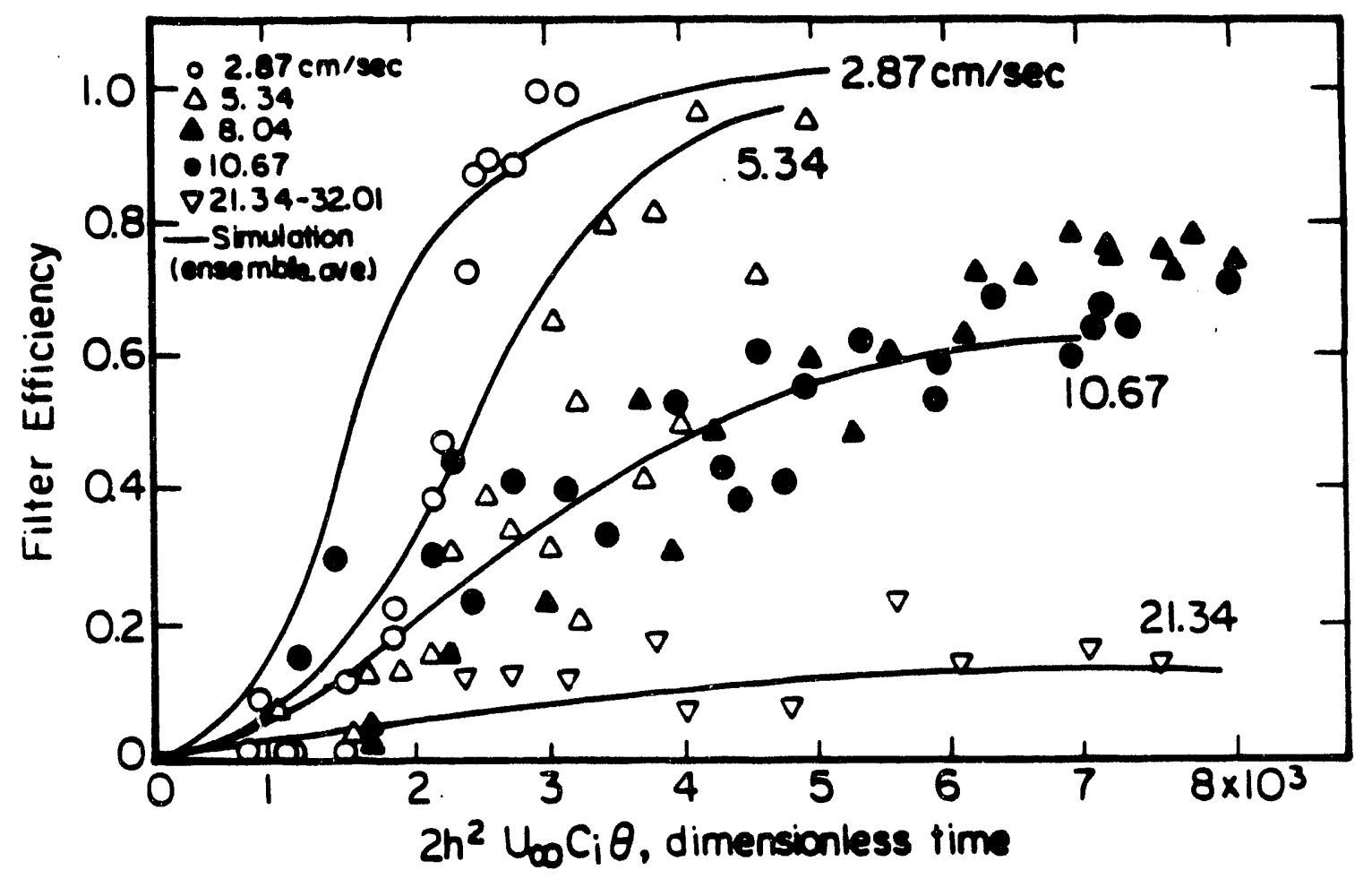

Fig. 4 Comparison between simulation and experiments of aerosol filtration in model fibrous filters (Tsiangetal. 1982). Model fitters were composed of parallel fibers with the ratio of fiber to interiber distance (from center to center), af $/ 2 \mathrm{~h}$, equal 100.25 and $2 a_{f}=25 \mu \mathrm{m}$. 


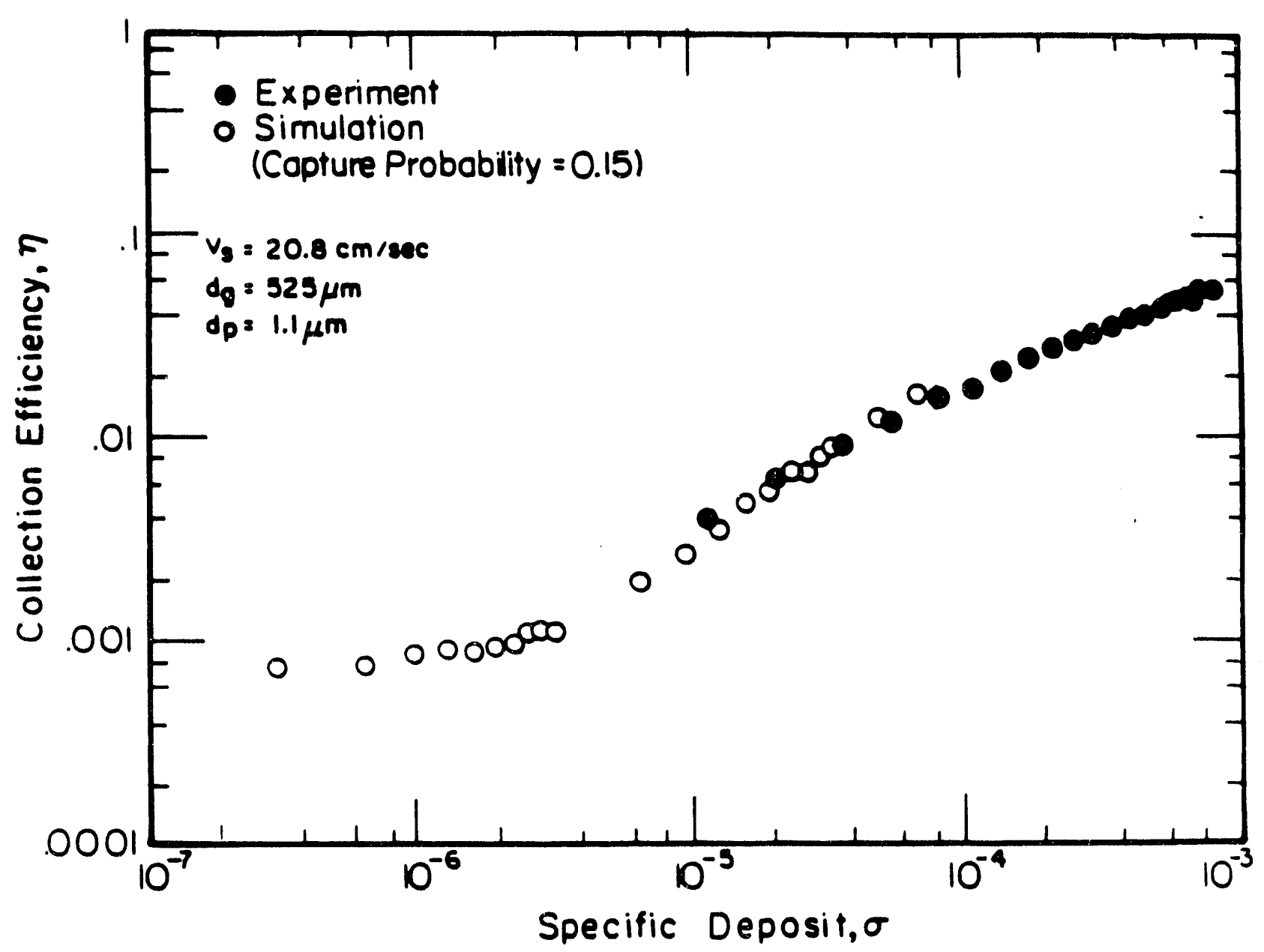

Fig. 5 Comparison between predicted $\eta$ vs $\sigma$ with experiments of aerosol filtration in granules. 

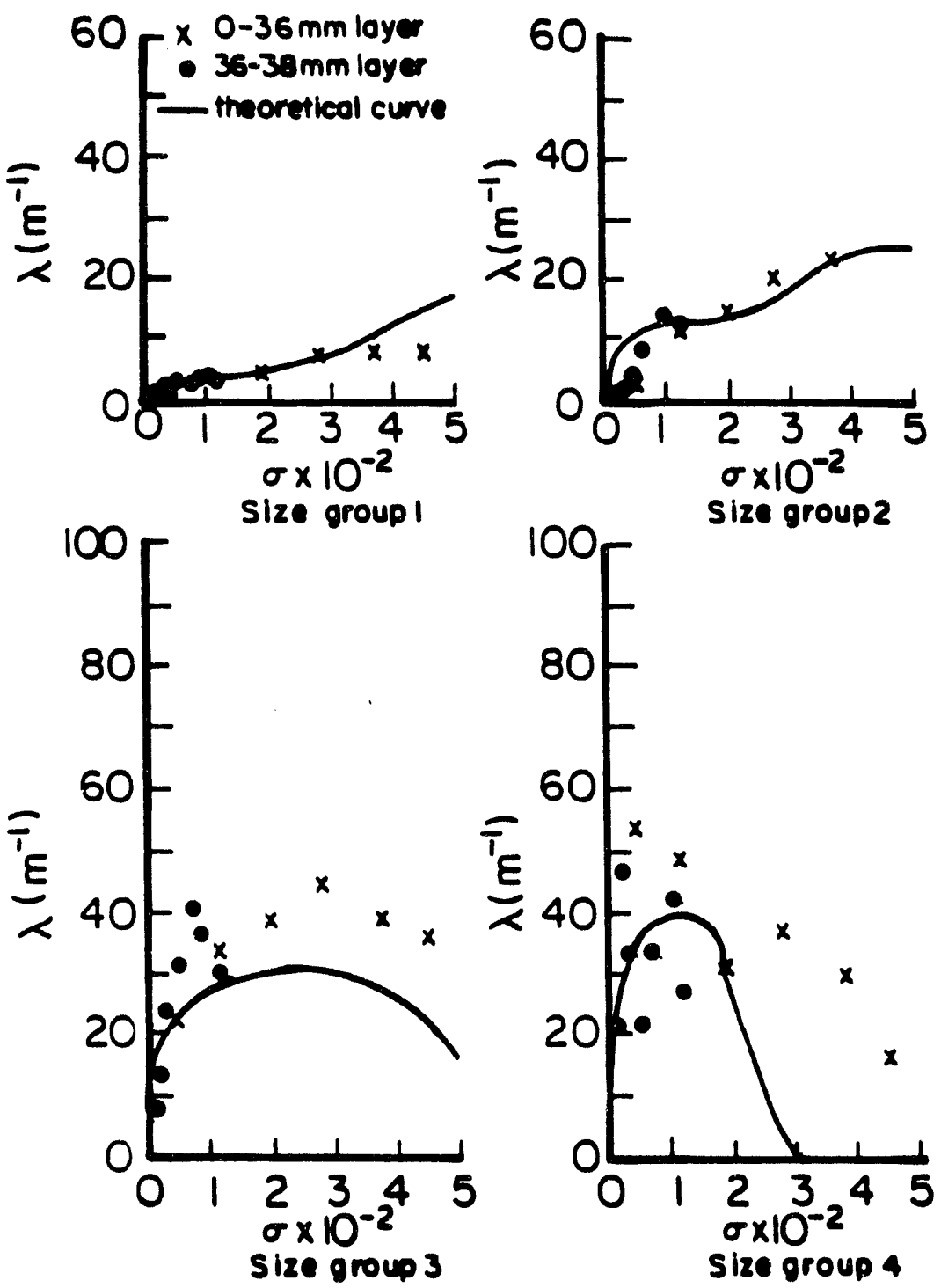

Fig. 6 Comparison between predicted $\eta$ vs $\sigma$ with experiments of hydrosol Nitration in granular beds (Mackie et al, 1987). Experiments were pertormed in fitters with grains of size Brittsh sieve 22-25 at $u_{s}=7.2 \mathrm{~m} \mathrm{~h}^{-1}$, particlo stzo:

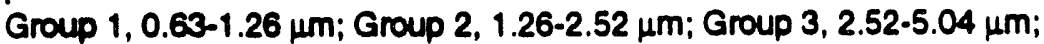
and Group 4, 5.04-10.98 $\mu \mathrm{m}$. 


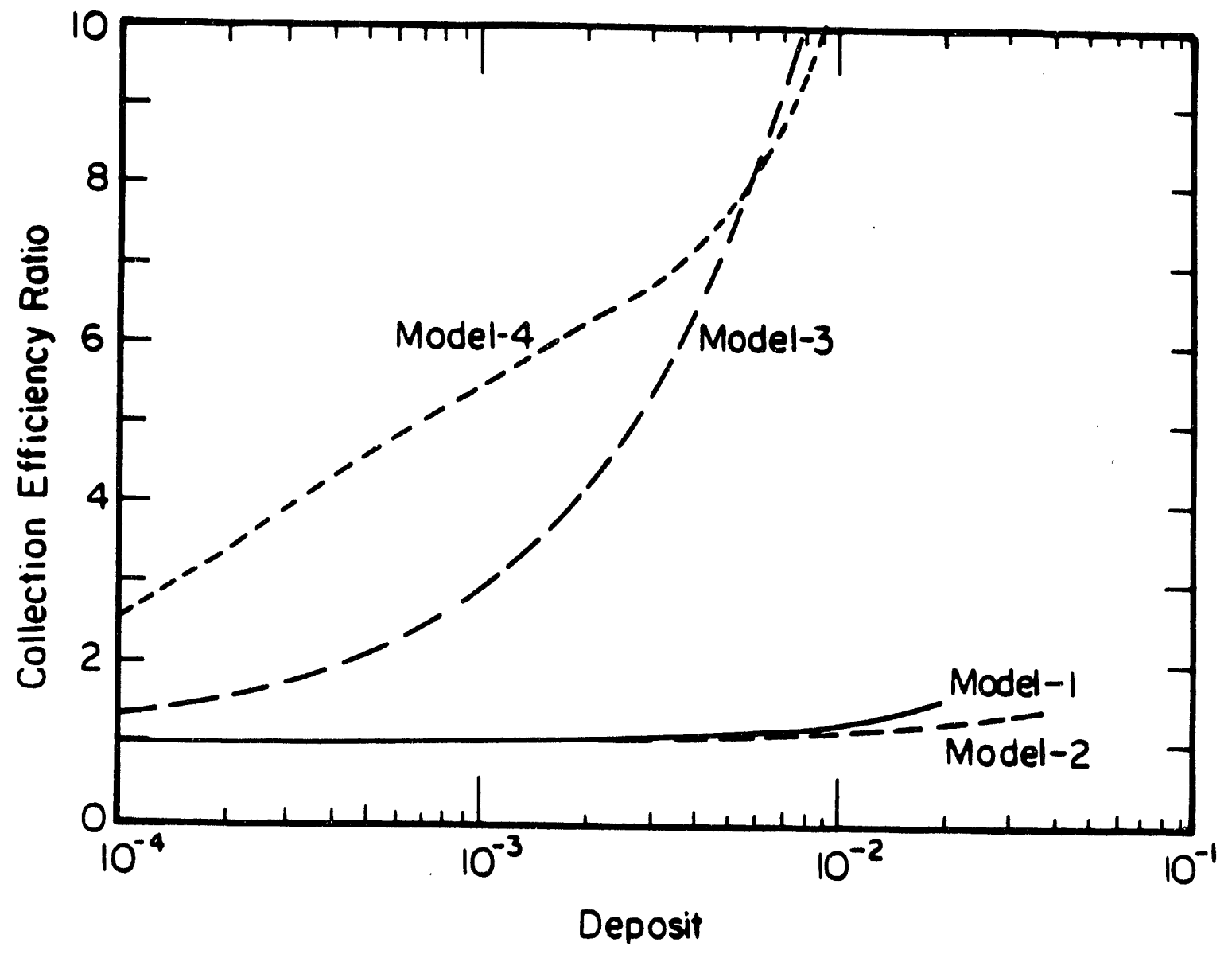

Fig. 7 Comparison of predictions of $F$ vs $\sigma$ according to four different models: Model 1, Tien fet al. (1979); Model 2, OMalia and All (1978); Model 3. Chiang and Tien (1985b); and Model 4, Mackie et al (1987) for hydrosol filtration under the following conditions:

$d_{p}=26 \mu \mathrm{m}, d_{g}=505 \mu \mathrm{m}, u_{s}=0.2 \mathrm{~cm} \mathrm{~s}^{-1}, \varepsilon_{g}=0.41$. 

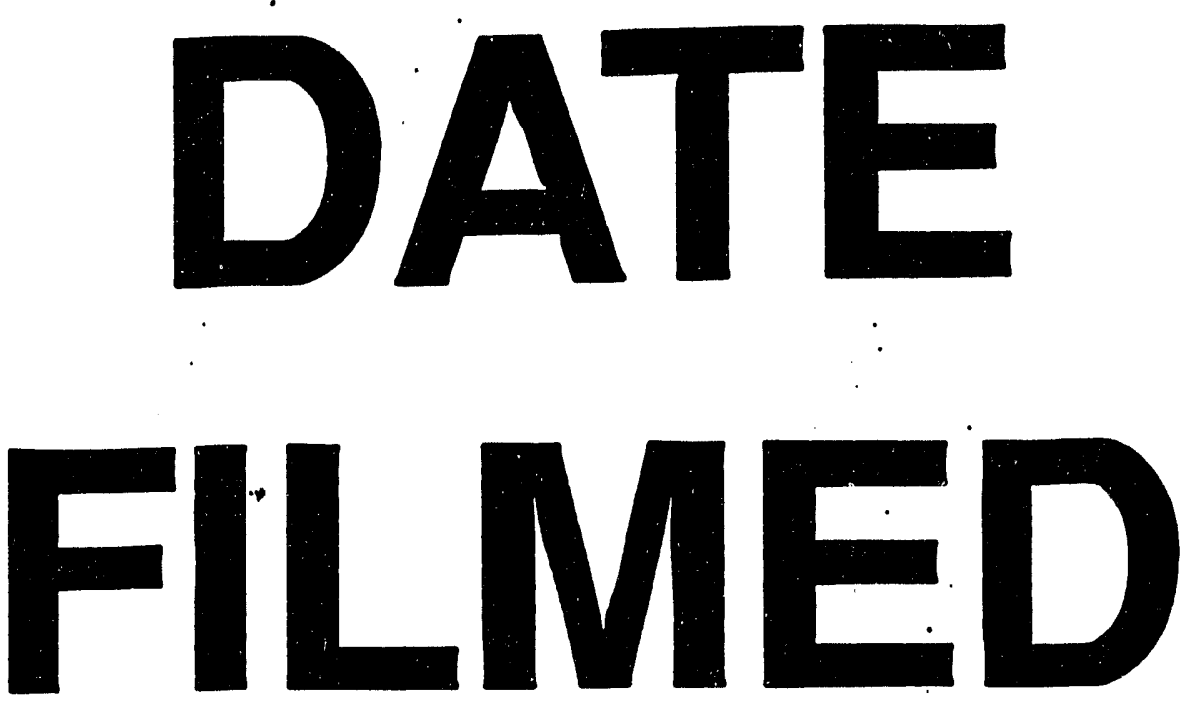

$1 / 26 / 94$
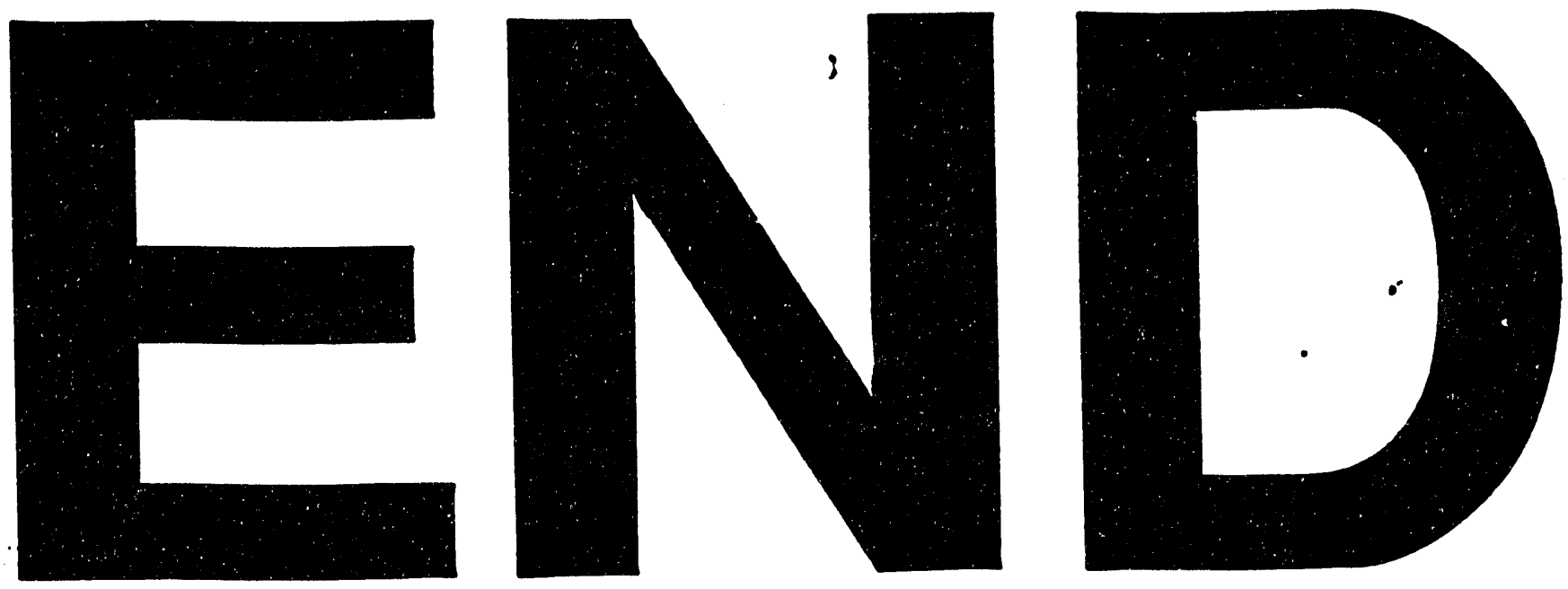
